OPEN ACCESS

Edited by:

Darío Ortiz De Orué Lucana, University of Osnabrück, Germany

Reviewed by: Haike Antelmann, Free University of Berlin, Germany Lars E. P. Dietrich,

Columbia University, USA

*Correspondence:

Jung-Hye Roe

jhroe@snu.ac.kr

tThese authors have contributed equally to this work.

Specialty section: This article was submitted to Microbial Physiology and Metabolism, a section of the journal

Frontiers in Microbiology

Received: 04 November 2016

Accepted: 19 January 2017

Published: 02 February 2017

Citation:

Lee K-L, Yoo J-S, Oh G-S,

Singh AK and Roe J-H (2017)

Simultaneous Activation of Ironand Thiol-Based Sensor-Regulator

Systems by Redox-Active

Compounds. Front. Microbiol. 8:139.

doi: 10.3389/fmicb.2017.00139

\section{Simultaneous Activation of Iron- and Thiol-Based Sensor-Regulator Systems by Redox-Active Compounds}

\author{
Kang-Lok Leet, Ji-Sun Yoo', Gyeong-Seok Oh, Atul K. Singh and Jung-Hye Roe* \\ School of Biological Sciences and Institute of Microbiology, Seoul National University, Seoul, South Korea
}

Bacteria in natural habitats are exposed to myriad redox-active compounds (RACs), which include producers of reactive oxygen species (ROS) and reactive electrophile species (RES) that alkylate or oxidize thiols. RACs can induce oxidative stress in cells and activate response pathways by modulating the activity of sensitive regulators. However, the effect of a certain compound on the cell has been investigated primarily with respect to a specific regulatory pathway. Since a single compound can exert multiple chemical effects in the cell, its effect can be better understood by time-course monitoring of multiple sensitive regulatory pathways that the compound induces. We investigated the effect of representative RACs by monitoring the activity of three sensorregulators in the model actinobacterium Streptomyces coelicolor; SoxR that senses reactive compounds directly through oxidation of its [2Fe-2S] cluster, CatR/PerR that senses peroxides through bound iron, and an anti-sigma factor RsrA that senses RES via disulfide formation. The time course and magnitude of induction of their target transcripts were monitored to predict the chemical activities of each compound in S. coelicolor. Phenazine methosulfate (PMS) was found to be an effective RAC that directly activated SoxR and an effective ROS-producer that induced CatR/PerR with little thiol-perturbing activity. $p$-Benzoquinone was an effective RAC that directly activated SoxR, with slower ROS-producing activity, and an effective RES that induced the RsrA-SigR system. Plumbagin was an effective RAC that activated SoxR, an effective ROS-producer, and a less agile but effective RES. Diamide was an RES that effectively formed disulfides and a weak RAC that activated SoxR. Monobromobimane was a moderately effective RES and a slow producer of ROS. Interestingly, benzoquinone induced the SigR system by forming adducts on cysteine thiols in RsrA, revealing a new pathway to modulate RsrA activity. Overall, this study showed that multiple chemical activities of a reactive compound can be conveniently monitored in vivo by examining the temporal response of multiple sensitive regulators in the cell to reveal novel activities of the chemicals.

Keywords: redox-sensitive regulators, Fe-S cluster, cysteine thiol, reactive electrophiles, quinones, actinobacteria 


\section{INTRODUCTION}

Bacteria are constantly exposed to oxidative stress conditions induced by diverse redox-active chemical compounds encountered in the environment, whether in abiotic natural habitats or at the interphase with plant or animal hosts. When they penetrate cell membranes, some redox-active compounds (RACs) generate reactive oxygen species (ROS) such as superoxide anions and peroxides via redox cycling (Imlay, 2013). Other RACs directly oxidize targets in the absence of redox cycling activity (Okegbe et al., 2012). Reactive electrophile species (RES) form disulfides or S-conjugated products on sensitive cysteine thiols of proteins and small molecules such as glutathione or its equivalents, including mycothiol and bacillithiol (Rudolph and Freeman, 2009; Jacobs and Marnett, 2010; Hillion and Antelmann, 2015).

Redox-active compounds include various phenazines and quinones produced by plants, fungi, and bacteria or synthetic derivatives administered as antibiotics or anticancer agents. Phenazines, a large group of nitrogen-containing heterocyclic compounds naturally produced by bacteria can alter cellular redox states and modify gene expression (Pierson and Pierson, 2010). Quinones are found in pigments, antibiotics, vitamin $\mathrm{K}$, coenzymes, and diverse anti-cancer drugs. They can modify cellular redox states and exert cytotoxicity by reacting with thiols or amine groups and generating ROS through redox cycling (O'Brien, 1991). Benzoquinones and naphthoquinones are known to be very electrophilic and thiol-reactive, readily forming ROS through a continuous cycle of reduction and autooxidation.

Cellular effects of RACs in vivo vary in different organisms, depending on multiple factors. These factors include their permeability, the presence of reductases to support redox cycling, the redox potential of possible targets, and the efficiency of systems that modify, degrade, and export molecules. For example, paraquat (methyl viologen) exerts its toxic effects through redox cycling, generating superoxide anions and ROS in plants, mammals, and Escherichia coli, but not in the actinobacterium Streptomyces coelicolor (Hassan and Fridovich, 1979; Bus and Gibson, 1984; Sheplock et al., 2013; Singh et al., 2013). Menadione (2-methyl-1,4-naphthoquinone; vitamin K3) and plumbagin (5-hydroxy-2-methyl-1,4-naphthoquinone) exert their toxic effects in Saccharomyces cerevisiae by generating ROS at millimolar concentrations and by S-thiolation at micromolar concentrations, respectively (Castro et al., 2008). In E. coli, however, menadione and plumbagin generate similar amounts of ROS and toxicity at 100-micromolar concentrations (Farr and Kogoma, 1991). Therefore, generalization based on studies from a few limited model systems may be insufficient to reveal the actual cellular effects. Considering the complexity of redox reactions, examining the cellular effects of RACs in a broader range of organisms is necessary to understand these reactions.

Streptomyces coelicolor is an actinobacterial model organism that inhabits soil. Streptomycetes produce a diverse array of antibiotics and bio-modulatory molecules, and are equipped with equally diverse mechanisms to sense and respond to these metabolites that are produced endogenously or exogenously (Bentley et al., 2002; Hopwood, 2007). Several sensor-regulators that respond to RACs have been elucidated in S. coelicolor (den Hengst and Buttner, 2008). They include SoxR, which senses RACs directly through oxidation of its $[2 \mathrm{Fe}-2 \mathrm{~S}]$ cluster (Singh et al., 2013; Lee et al., 2015), OxyR and CatR that sense peroxides (Hahn et al., 2000, 2002), OhrR that senses organic peroxides (Oh et al., 2007), Rex that senses NADH/NAD+ (Brekasis and Paget, 2003), [4Fe-4S]-containing NsrR that senses nitric oxide (Tucker et al., 2008; Crack et al., 2015), and the Zn-containing anti-sigma factor RsrA that senses RES through zinc-coordinating cysteine residues (Kang et al., 1999; Park and Roe, 2008; Rajasekar et al., 2016). In response to each triggering compound, these sensorregulators induce a few to 100 s of genes to defend cells against the damaging effects of the compounds. For example, activated (oxidized) SoxR induces several genes that may function in export and redox modifications (Dietrich et al., 2008; Dela Cruz et al., 2010; Shin et al., 2011; Naseer et al., 2014). Oxidized CatR, an ortholog of PerR from Bacillus subtilis (Lee and Helmann, 2006), derepresses the catA gene encoding a catalase (Hahn et al., 2000). Upon oxidation, RsrA dissociates from its binding partner SigR (Kang et al., 1999), which then induces more than 100 direct target genes related with thiol reduction, thiol synthesis, recycling of the small thiol molecule mycothiol (MSH), and protein quality control (Kim et al., 2012). Mycothiol, the functional equivalent of glutathione in actinobacteria as bacillithiol in firmicutes, maintains thiol redox homeostasis and detoxifies reactive electrophiles (Newton et al., 2008; Park and Roe, 2008; Gaballa et al., 2010).

In this study, the intracellular effects of several redoxperturbing chemicals were monitored by assessing the activity of three representative redox-sensitive regulators in S. coelicolor: SoxR, CatR, and RsrA. The [2Fe-2S] of SoxR in S. coelicolor (ScSoxR) is not oxidized by superoxide, but is directly oxidized by some RACs (Singh et al., 2013). In aerobically grown E. coli, where paraquat can generate superoxide anion radical, heterologously expressed SoxR from S. coelicolor (ScSoxR) is not activated (Singh et al., 2013). SoxR from E. coli (EcSoxR) can be directly oxidized by RACs such as paraquat under anaerobic condition or inside $S$. coelicolor cells where paraquat does not produce superoxide (Gu and Imlay, 2011; Singh et al., 2013). EcSoxR can be oxidized by superoxide as well (Fujikawa et al., 2016). Therefore, ScSoxR is a specific sensor for [2Fe-2S]-oxidizing RACs rather than ROS, to which CatR/PerR responds. RsrA is known to be oxidized by diamide and by other RES that can deplete MSH pool by conjugation (Paget et al., 1998; Kang et al., 1999; Park and Roe, 2008), and hence is a suitable sensor for thiol perturbation. Disulfide bond formation between conserved zinc-coordinating cysteines has been shown to inactivate RsrA (Li et al., 2003; Bae et al., 2004; Rajasekar et al., 2016). Whether, RsrA is directly alkylated by RES has not been shown. The time-course of induction of their target gene transcripts was monitored to obtain insights into the redox signals that these compounds may generate in cells. 


\section{MATERIALS AND METHODS}

\section{Strains, Plasmids, Chemicals, and Growth Conditions}

Spores of S. coelicolor A3(2) strain M145 were inoculated into YEME liquid medium containing $10 \%$ sucrose and incubated at $30^{\circ} \mathrm{C}$ (Kieser et al., 2000). $\gamma$-Actinorhodin was isolated from a plate culture of $S$. coelicolor M145 cells on R2YE as described previously (Shin et al., 2011). E. coli cells were grown in Luria-Bertani (LB) medium at $37^{\circ} \mathrm{C}$. Toxoflavin was kindly provided by Prof. Ingyu Hwang (College of Agricultural Life Sciences, SNU). Other chemicals were obtained from Sigma-Aldrich. The chemical stock solutions were prepared fresh at $100 \mathrm{mM}$ concentrations before each treatment, and used in treatments at final concentrations of actinorhodin $(200 \mathrm{nM})$, pyocyanin $(10 \mu \mathrm{M})$, toxoflavin $(20 \mu \mathrm{M})$, phenazine methosulfate $(50 \mu \mathrm{M})$, paraquat $(200 \mu \mathrm{M})$, plumbagin (25-50 $\mu \mathrm{M})$, menadione sodium bisulfite (MDs, $500 \mu \mathrm{M}$ ), menadione $(\mathrm{MD}, 350 \mu \mathrm{M}), p$-benzoquinone $(50 \mu \mathrm{M})$, diamide $(500 \mu \mathrm{M})$, and monobromobimane $(20 \mu \mathrm{M})$.

\section{RNA Preparation and S1 Nuclease Protection Assay}

Streptomyces coelicolor cells grown to an $\mathrm{OD}_{600}$ of $0.3-0.4$ in YEME were treated with various chemicals for 5-120 min. Harvested cells were disrupted by sonication in Kirby mix. RNA was isolated and the S1 nuclease protection assay was performed as described previously (Kieser et al., 2000). For each assay, $50 \mu \mathrm{g}$ RNA was used to analyze SCO2478 and catA transcripts, and $20 \mu \mathrm{g}$ RNA was used to analyze sigR transcripts. To generate gene-specific S1 mapping probes, PCR products encompassing $\operatorname{sig} R(-265$ to $+80 \mathrm{nt}$ relative to the start codon), SCO2478 $(-177$ to $+100 \mathrm{nt}$ relative to the start codon), and cat $A(-115$ to +153 $\mathrm{nt}$ relative to the start codon) promoter regions were obtained.

\section{Fluorescence Measurement of Intracellular ROS}

Exponentially grown $S$. coelicolor cells $\left(\mathrm{OD}_{600} \sim 0.2-0.3\right)$ were treated with the indicated amounts of each chemical for $30 \mathrm{~min}$, followed by harvest of the cells by centrifugation for $3 \mathrm{~min}$ at $5,000 \times g$ at $4^{\circ} \mathrm{C}$. Cell pellets were briefly washed twice with ice-cold $\mathrm{P}$ buffer [103 $\mathrm{mg} / \mathrm{l}$ sucrose, $0.25 \mathrm{mg} / \mathrm{l}$ potassium sulfate, $2 \mathrm{ml}$ trace element solution, $0.05 \mathrm{mg} / \mathrm{l} \mathrm{KH}_{2} \mathrm{PO}_{4}$, $2.03 \mathrm{mg} / \mathrm{l} \mathrm{MgCl}_{2} \cdot 6 \mathrm{H}_{2} \mathrm{O}, 3.68 \mathrm{mg} / \mathrm{l} \mathrm{CaCl}_{2} \cdot 2 \mathrm{H}_{2} \mathrm{O}$, and $100 \mathrm{ml}$ $0.25 \mathrm{M}$ TES buffer ( $\mathrm{pH}$ 7.2)]. The trace element solution contained $40 \mathrm{mg} / \mathrm{l} \mathrm{ZnCl} 2,200 \mathrm{mg} / \mathrm{ml} \mathrm{FeCl} 3 \cdot 6 \mathrm{H}_{2} \mathrm{O}, 10 \mathrm{mg} / \mathrm{ml}$ $\mathrm{CuCl}_{2} \cdot 2 \mathrm{H}_{2} \mathrm{O}, 10 \mathrm{mg} / \mathrm{ml} \mathrm{MnCl} \cdot 4 \mathrm{H}_{2} \mathrm{O}, 10 \mathrm{mg} / \mathrm{l} \mathrm{Na}{ }_{2} \mathrm{~B}_{4} \mathrm{O}_{7} \cdot 10 \mathrm{H}_{2} \mathrm{O}$, and $10 \mathrm{mg} / \mathrm{l}\left(\mathrm{NH}_{4}\right)_{6} \mathrm{Mo}_{7} \mathrm{O}_{24} \cdot 4 \mathrm{H}_{2} \mathrm{O}$ (Kieser et al., 2000). Cells were resuspended in pre-warmed $\mathrm{P}$ buffer containing $5 \mu \mathrm{M}$ $\mathrm{DCFH}_{2}$-DA (2'-7'-dichlorofluorescein diacetate; Sigma) and incubated for $30 \mathrm{~min}$ at $30^{\circ} \mathrm{C}$ in the dark. Intracellular conversion of $\mathrm{DCFH}_{2}$-DA by esterase in the cell produces non-fluorescent $\mathrm{DCFH}_{2}$, which can be oxidized by ROS to produce fluorescent DCF (Keston and Brandt, 1965; Bass et al., 1983). DCF fluorescence was measured in a fluorometric plate reader (EnVision Multilabel Plate Readers, Perkin Elmer) with excitation and emission at 492 and $535 \mathrm{~nm}$, respectively. The optical density of each sample was measured at $600 \mathrm{~nm}$ in a spectrophotometric plate reader (PowerWave X, BioTek) to normalize the fluorescence by the amount of cells in each well.

\section{Western Blot Analysis of the Redox States of RsrA}

Exponentially grown $S$. coelicolor cells $\left(\mathrm{OD}_{600} \sim 0.3-0.4\right)$ were treated with $0.5 \mathrm{mM}$ diamide or $50 \mu \mathrm{M}$ benzoquinone for 5-60 min, followed by fixation with $10 \%$ trichloroacetic acid (TCA) for $20 \mathrm{~min}$ on ice. The fixed cells from $15 \mathrm{ml}$ cultures were harvested and ruptured in $12.5 \%$ TCA with sonication. Precipitated proteins were washed twice with cold acetone, solubilized in TSE buffer (50 mM Tris- $\mathrm{HCl}$ at $\mathrm{pH} 7.5,0.1 \%$ sodium dodecyl sulfate [SDS], $10 \mathrm{mM}$ EDTA) containing 10 mM AMS (4-acetamido-4'-maleimidylstilbene-2,2' -disulfonic acid; MW 536.4), and incubated at room temperature for $2 \mathrm{~h}$. Solubilized proteins were precipitated with 10\% TCA, washed with acetone twice, and dissolved in $100 \mathrm{ml}$ TSE buffer. Protein samples were mixed with SDS loading buffer containing $50 \mathrm{mM}$ dithiothreitol (DTT) and resolved by 15\% SDS-polyacrylamide electrophoresis (PAGE). Purified RsrA was run in parallel, with or without AMS treatment in the presence of DTT, to indicate the positions of fully reduced RsrA (up to 7 ASM-adducts per molecule) or oxidized RsrA, respectively. After electrophoresis, the proteins were transferred to a nitrocellulose membrane, followed by blocking with skim milk. Immuno-detection was performed using a polyclonal rabbit antibody against RsrA protein (AbClon), with the anti-rabbit IgG secondary antibody (Santacruz) diluted to 1:5000 and 1:3000, respectively, followed by enhanced chemilumenescence (ECL) detection (Amersham Life Science). To determine the amount of total RsrA in each sample, cell extracts were mixed with SDS loading buffer, followed by $15 \%$ SDS-PAGE and Western blot analysis.

\section{Purification of RsrA and Analysis of its Thiol-Modified Forms}

His-tagged RsrA was overproduced in E. coli BL21( $\lambda$ DE3)pLys harboring pET15b-RsrA, followed by purification with an $\mathrm{Ni}$ NTA column as described previously (Kang et al., 1999). After removing the His-tag with thrombin, RsrA was purified by gel filtration chromatography on a HiLoad Superdex 75 column (GE Healthcare) in $\mathrm{TN}$ buffer (40 mM Tris- $\mathrm{HCl}$ at $\mathrm{pH} 7.5$, $0.2 \mathrm{mM} \mathrm{NaCl}$ ). Purified proteins were quantified using Pierce BCA Protein Assay Kit (Thermo Scientific). Reduced RsrA was prepared by incubating $200 \mathrm{nM}$ RsrA in $10 \mathrm{mM} \mathrm{DTT}$ at $25^{\circ} \mathrm{C}$ for $1 \mathrm{~h}$, with the subsequent addition of $400 \mathrm{nM} \mathrm{ZnSO}_{4}$ for $1 \mathrm{~h}$ in an anaerobic chamber (Coy) with $5 \% \mathrm{H}_{2}, 5 \% \mathrm{CO}_{2}$, and $90 \%$ $\mathrm{N}_{2}$. Free zinc and DTT was removed by using a PD-10 desalting column and anaerobically prepared TN buffer. To analyze parabenzoquinone (BQ)-modified RsrA, $100 \mathrm{nM}$ reduced RsrA in $300 \mu \mathrm{L}$ buffer was treated with $50 \mu \mathrm{M}$ BQ for 10 or $20 \mathrm{~min}$, and electrophoresed on SDS-PAGE followed by silver staining. For mass analysis, $50 \mu \mathrm{M}$ reduced RsrA in $300 \mu \mathrm{L}$ buffer was treated with $1 \mathrm{mM}$ BQ for $20 \mathrm{~min}$, followed by denaturation in $8 \mathrm{M}$ urea. 


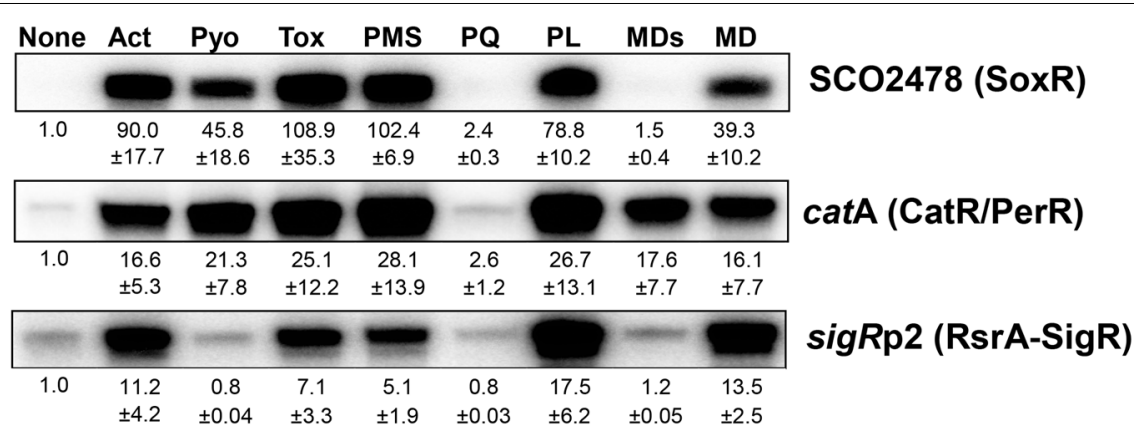

FIGURE 1 | Differential activation of redox-sensitive regulators by redox-active compounds (RACs) in Streptomyces coelicolor. Exponentially grown S. coelicolor cells $\left(\mathrm{OD}_{600}\right.$ 0.4-0.5) were treated with the following RACs for 30 min: actinorhodin (Act, $\left.200 \mathrm{nM}\right)$, pyocyanin (Pyo, $\left.10 \mu \mathrm{M}\right)$, toxoflavin (Tox, $\left.20 \mu \mathrm{M}\right)$, phenazine methosulfate (PMS, $50 \mu \mathrm{M})$, paraquat (PQ, $200 \mu \mathrm{M})$, plumbagin ( $\mathrm{PL}, 25 \mu \mathrm{M})$, menadione sodium bisulfite (MDs, $500 \mu \mathrm{M})$, and menadione (MD, $350 \mu \mathrm{M})$. Activity modulation of SoxR, CarR/PerR, and RsrA-SigR sensor-regulators was monitored by S1 mapping of their target gene transcripts, SCO2478, catA, and sigRp2, respectively. Average fold induction values with standard deviations were obtained from three to five independent experiments.

\section{LC-MS/MS Analysis}

Analytical capillary columns $(100 \mathrm{~cm} \times 75 \mu \mathrm{m}$ i.d. $)$ and trap columns $(2 \mathrm{~cm} \times 150 \mu \mathrm{m}$ i.d) were packed in-house with $3 \mu \mathrm{m}$ Jupiter C18 particles (Phenomenex, Torrance, CA, USA). The long analytical column was placed in a column heater (Analytical Sales and Services, Pompton Plains, NJ, USA) regulated to a temperature of $45^{\circ} \mathrm{C}$. Dionex Ultimate 3000 RSLC nano-system (Thermo Scientific, Sunnyvale, CA, USA) was operated at a flow rate of $350 \mathrm{~nL} / \mathrm{min}$ over $110 \mathrm{~min}$ with linear gradient ranging from $95 \%$ solvent $\mathrm{A}\left(\mathrm{H}_{2} \mathrm{O}\right.$ with $0.1 \%$ formic acid) to $40 \%$ of solvent B (acetonitrile with $0.1 \%$ formic acid). The peptide samples were analyzed on a Q-Exactive mass spectrometer (Thermo Scientific) equipped with an in-house customized nanoelectrospray ion source. Precursor ions were acquired $(\mathrm{m} / \mathrm{z}$ $400-1800$ ) at $70 \mathrm{~K}$ resolving power and the isolation of precursor for MS/MS analysis was performed with a 2.0 Th. Higher-energy collisional dissociation (HCD) with $25 \%$ collision energy was used for sequencing with a target value of $1 \mathrm{e} 6$ ions determined by automatic gain control. Resolving power for acquired MS2 spectra was set to 17,500 at $\mathrm{m} / \mathrm{z} 200$ with $60 \mathrm{~ms}$ maximum injection time. All MS/MS data were searched by MS-GF+ algorithm (v.9979) at $10 \mathrm{ppm}$ of precursor ion mass tolerance against UniProt S. coelicolor DB (entry 8171, Oct 18 2016). The following search parameters were applied: semi-tryptic digestion, and dynamic BQ (delta monoisotopic mass: 108.021) of cysteine residue. The false discovery rate (FDR) was set at $1 \%$ for peptide spectrum match including unlabeled peptides resulting in zero FDR for the labeled peptides.

\section{RESULTS AND DISCUSSION}

\section{Modulation of the Activity of Redox-Sensitive Regulators in S. coelicolor by Redox-Active Compounds}

We previously determined whether various natural or synthetic RACs, regardless of superoxide production, are sensed by the
[2Fe-2S]-based regulator SoxR in S. coelicolor (Singh et al., 2013). To extend that analysis, we investigated whether these chemicals affect CatR and RsrA, which sense peroxide and thiol-reactive compounds, respectively, by quantifying transcripts from their direct target genes. Figure 1 shows the responsiveness of SoxR, CatR, and RsrA to actinorhodin (Act, $200 \mathrm{nM}$ ), pyocyanin (Pyo, $10 \mu \mathrm{M}$ ), toxoflavin (Tox, $20 \mu \mathrm{M}$ ), phenazine methosulfate (PMS, $50 \mu \mathrm{M}$ ), methyl viologen (paraquat, $\mathrm{PQ}, 200 \mu \mathrm{M}$ ), plumbagin (PL, $25 \mu \mathrm{M}$ ), menadione bisulfite (MDs, $500 \mu \mathrm{M}$ ), and menadione $(\mathrm{MD}, 350 \mu \mathrm{M})$ at 30 min post-treatment. The results show that each RAC activates the three regulons differentially. Actinorhodin, toxoflavin, and plumbagin effectively activated all three regulons, whereas pyocyanin activated SoxR and CatR/PerR but did not activate RsrA effectively. Paraquat did not activate any of the three regulons, consistent with a previous suggestion that it does not redox cycle to produce ROS in S. coelicolor, even though it is redox active to activate E. coli SoxR in S. coelicolor cells (Singh et al., 2013). On the other hand, menadione bisulfite did not activate SoxR, but activated the CatR regulon, suggestive of redox-cycling activity in $S$. coelicolor. Phenazine methosulfate effectively induced SoxR and CatR target genes, and RsrASigR to a lesser extent, similar to the effects of pyocyanin. The induction profiles by these compounds were snapshots obtained $30 \mathrm{~min}$ after treatment. Therefore, it is not certain whether the modulation of activity occurred immediately or in a delayed fashion through indirect effects. To resolve this issue, we chose representative RACs and monitored the time courses of their effects on the three regulators.

Figure 2A illustrates the activation mechanism of each transcriptional regulator. The $[2 \mathrm{Fe}-2 \mathrm{~S}]^{1+}$ cluster of SoxR in each monomeric unit is oxidized directly by RAC to $[2 \mathrm{Fe}-2 \mathrm{~S}]^{2+}$, which changes the binding pattern of SoxR to the promoter region, to activate open complex formation between RNA polymerase and the promoter (Watanabe et al., 2008; Singh et al., 2013; Lee et al., 2015). PerR senses $\mathrm{H}_{2} \mathrm{O}_{2}$ via bound $\mathrm{Fe}^{2+}$, which elicits Fenton reaction and oxidation of nearby histidine residues, subsequently leading to the loss of DNA-binding ability of PerR (Lee and Helmann, 2006; Parent et al., 2013). The five amino acids that are critical to sense $\mathrm{H}_{2} \mathrm{O}_{2}$ in PerR are all 
A
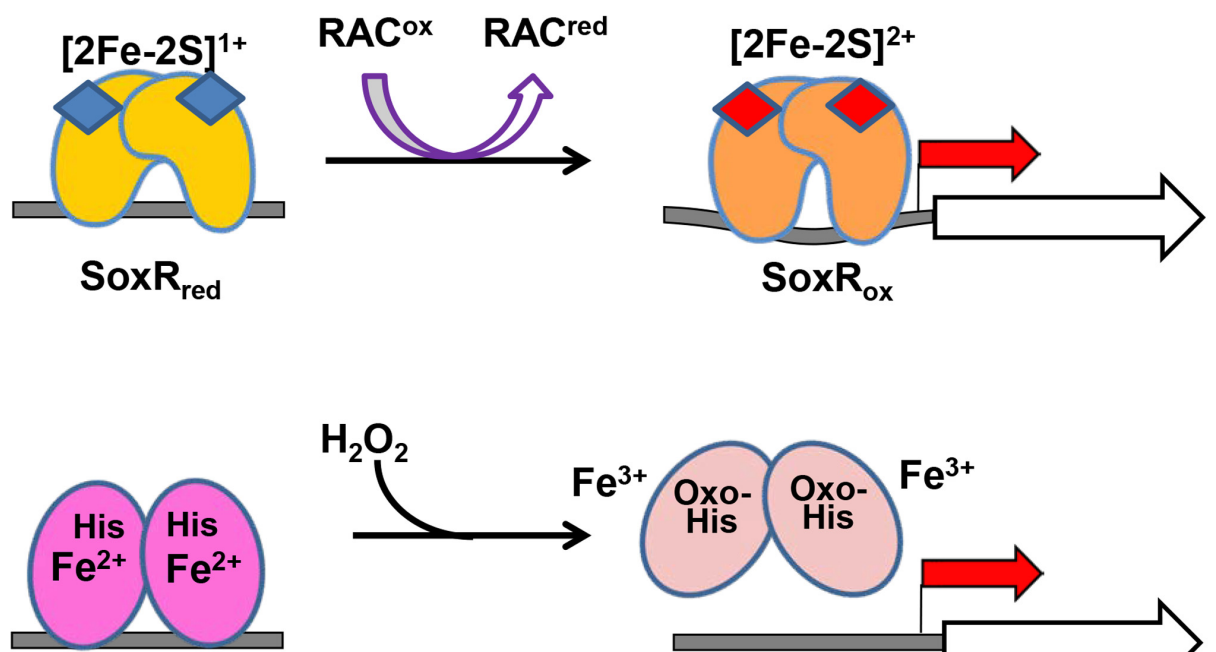

CatR/PerR red

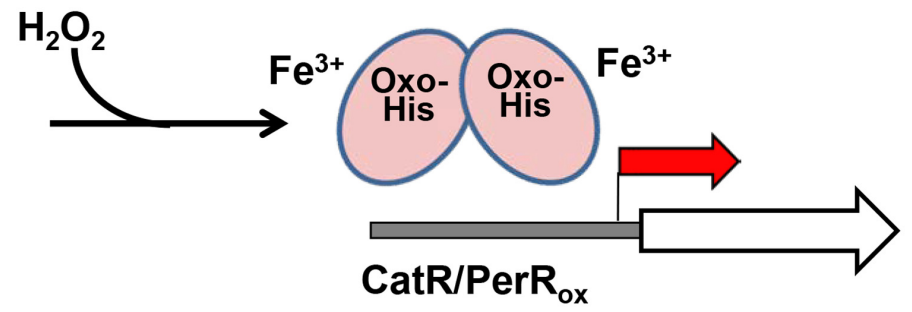

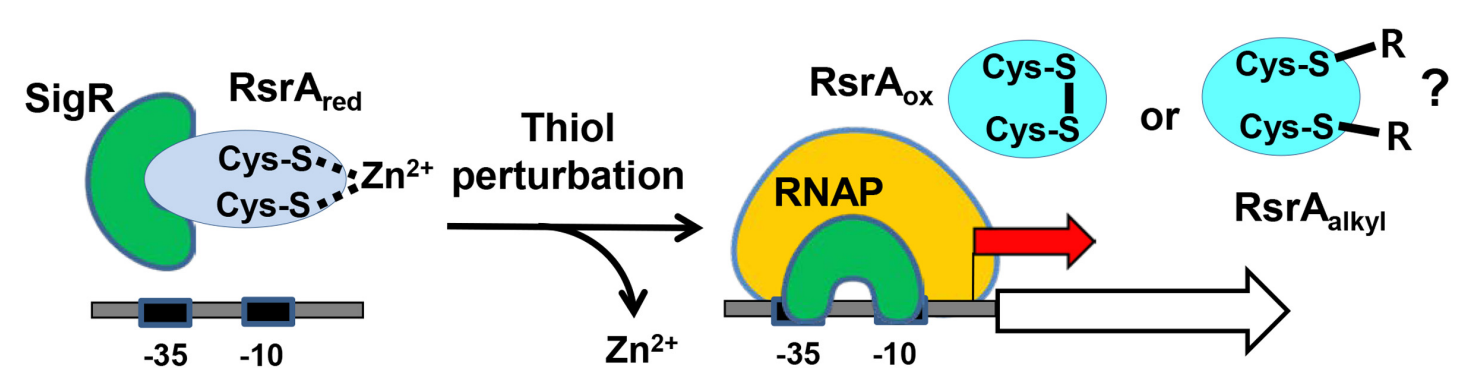

B

\section{Phenazine methosulfate (PMS)}<smiles>COS(=O)(=O)O</smiles>

ROS producing RAC

$$
\begin{aligned}
& \text { Plumbagin } \\
& \text { (PL) }
\end{aligned}
$$<smiles>CC1=CC(=O)c2c(O)cccc2C1=O</smiles>

ROS producing RAC, RES

\section{p-Benzoquinone}

(BQ)<smiles>O=C1C=CC(=O)C=C1</smiles>

ROS producing RAC, RES

\section{Diamide (DA)}<smiles>CN(C)C(=O)N=NC(=O)N(C)C</smiles>

RES (disulfide-former)

\section{Monobromobimane (mBBr)}<smiles>Cc1c(C)n2c(C)c(C)c(=O)n2c1=O</smiles>

RES

FIGURE 2 | The redox-sensing schemes of three regulators and the redox-active compounds examined in this study. (A) The active site metals and amino acid residues in the three sensor-regulators are shown, along with the compounds they react to and the changes they undergo. The redox state of [2Fe-2S] in SoxR changes upon interacting with RACs. The peroxide-sensing Fe ${ }^{2+}$ in CatR/PerR undergo Fenton reaction with $\mathrm{H}_{2} \mathrm{O}_{2}$ to produce hydroxyl radical, and the nearby His is oxidized to oxo-His. Thiol-perturbation by RES cause disulfide bond formation in RsrA to release SigR to transcribe its target genes. Whether RES alkylates RsrA has not been reported. (B) Redox-active compounds examined in this study. It is known that phenazine methosulfate (PMS) is an ROS-producer, plumbagin and p-benzoquinone are both ROS-producers and reactive electrophile species (RES), and that diamide and monobromobimane are RES. 


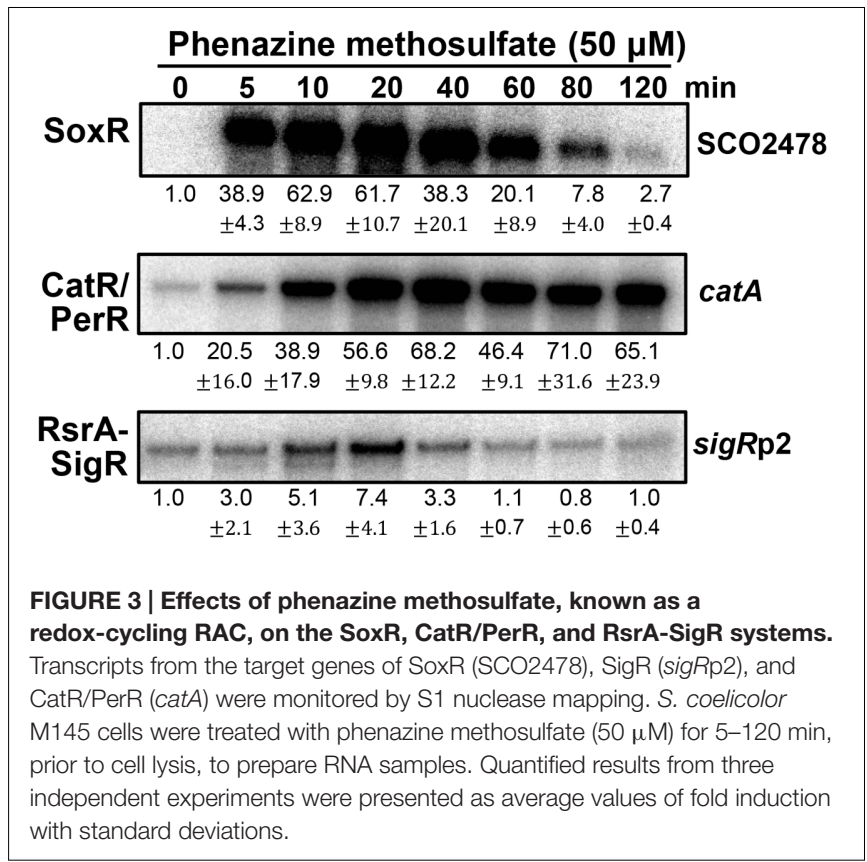

conserved in S. coelicolor CatR, supporting a similar sensing mechanism (Supplementary Figure S1). The reduced RsrA bound to SigR is oxidized via disulfide bond formation between $\mathrm{Zn}^{2+}$. coordinating cysteine residues by thiol- RES directly (diamide) or indirectly by depleting MSH via S-conjugation (Kang et al., 1999; Park and Roe, 2008; Rajasekar et al., 2016). Whether RES can inactivate RsrA by direct alkylation has not been reported, even though plausible.

Figure 2B shows the five compounds whose effects on the three regulators we monitored in vivo. PMS is a known redox-cycling RAC that can produce superoxide radicals and hence peroxides (Nishikimi et al., 1972). Plumbagin and BQ are known to be a redox-cycling RAC and RES (O'Brien, 1991; Castro et al., 2008). Diamide and monobromobimane are electrophiles with different propensities for reaction products. Whereas, diamide rapidly forms disulfide bonds between neighboring cysteine thiols (Kosower and Kosower, 1995), monobromobimane preferentially forms S-alkylated products on cysteine thiols (Kosower et al., 1979). We treated exponentially grown S. coelicolor cells with each compound for 5, 10, 20, 40, 60,80 , or $120 \mathrm{~min}$, and measured by $\mathrm{S} 1$ nuclease mapping the amount of transcripts from SCO2478, catA, and sigR promoters that were regulated by SoxR, CatR, and RsrA-SigR, respectively.

\section{Redox Signaling of PMS in S. coelicolor}

Figure 3 shows the effects of PMS on the activities of three regulators at sub-inhibitory doses (Lee et al., 2015). PMS strongly activated SoxR within $5 \mathrm{~min}$, consistent with its direct oxidation of $[2 \mathrm{Fe}-2 \mathrm{~S}]$. PMS also inactivated the CatR/PerR repressor (to induce cat $A$ expression) in less than $5 \mathrm{~min}$, suggesting that it can generate peroxide immediately after treatment. In contrast to the SoxR activation profile, the induction of CatR-regulated cat $A$ steadily increased for $40 \mathrm{~min}$ and then was sustained until $2 \mathrm{~h}$. A previous study showed that the induction of catA by $0.2 \mathrm{mM} \mathrm{H}_{2} \mathrm{O}_{2}$ lasted only about $40 \mathrm{~min}$, indicative of the limited duration of $\mathrm{H}_{2} \mathrm{O}_{2}$ following catalase induction (Hahn et al., 2000). Therefore, continuous generation of peroxides by PMS may serve to retain some level of intracellular peroxides to maintain CatR in an inactive form for up to $2 \mathrm{~h}$. The transient mode of SoxR activation by PMS suggests that PMS may be removed from the cell by $2 \mathrm{~h}$ post-treatment, likely because of export by one of the target gene products of SoxR (Dela Cruz et al., 2010; Shin et al., 2011). Induction of the SigRtarget gene by PMS through oxidizing RsrA appeared quite inefficient. This suggests that the amount of peroxides formed by
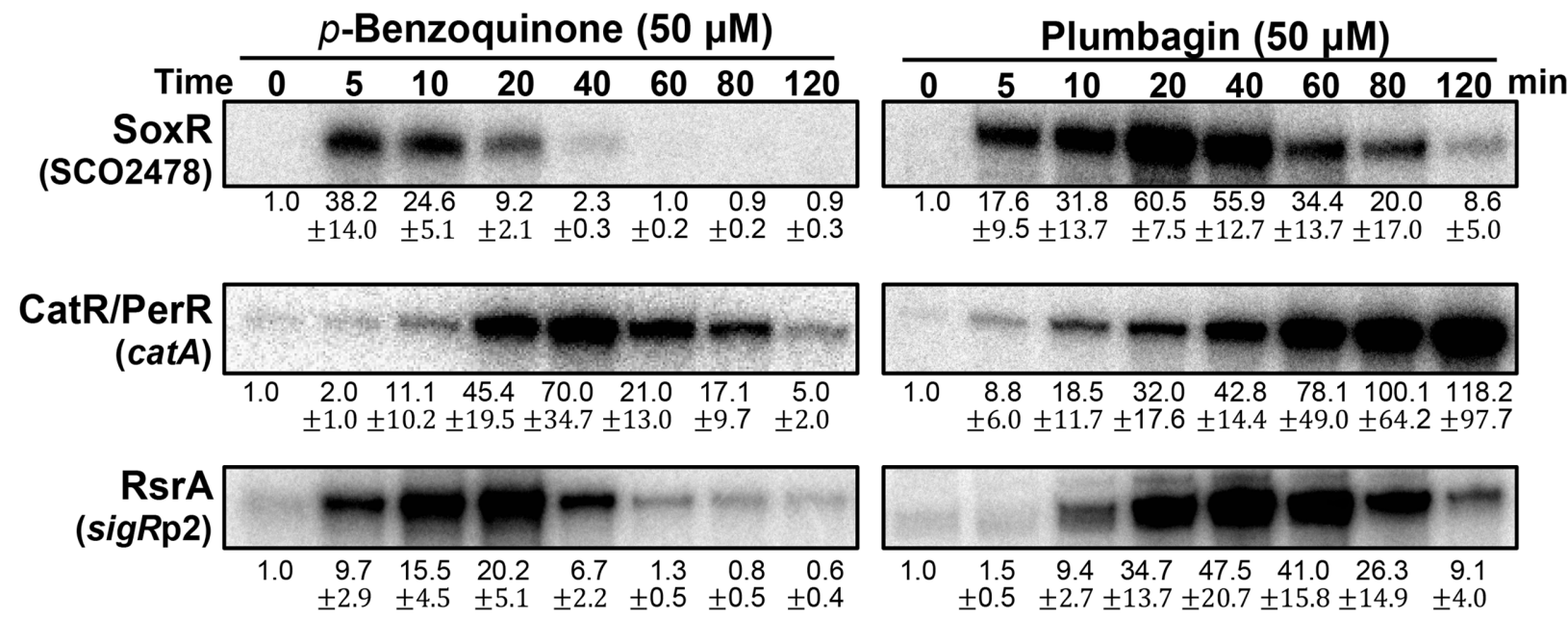

FIGURE 4 | Effects of $\boldsymbol{p}$-benzoquinone and plumbagin, known as ROS-producing RAC and RES. S. coelicolor cells were treated with either $p$-benzoquinone (50 $\mu \mathrm{M}$; A) or plumbagin (B) for 5-120 min. S1 mapping analysis and quantification of results from three independent experiments was performed as in Figure 3 . 
A

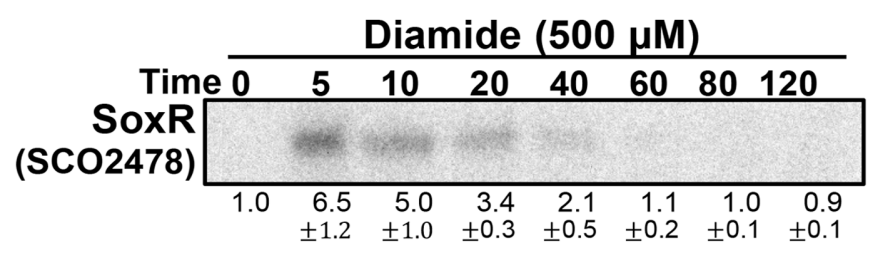

B

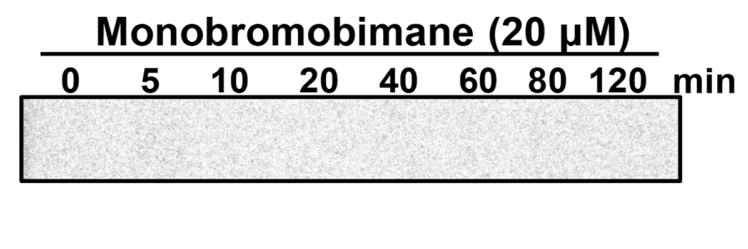

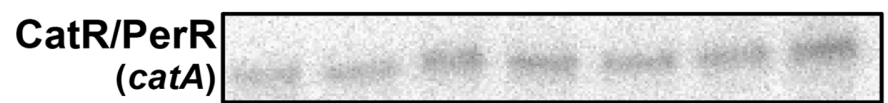

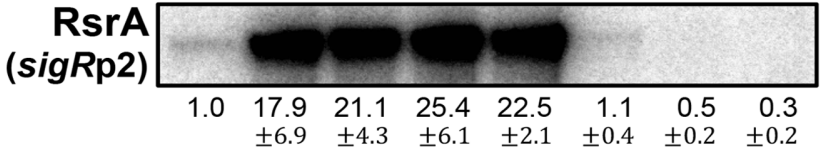

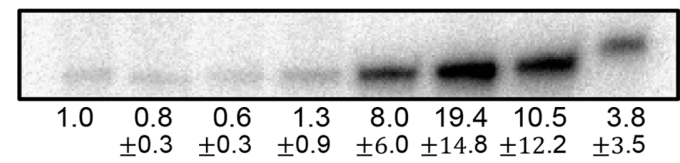

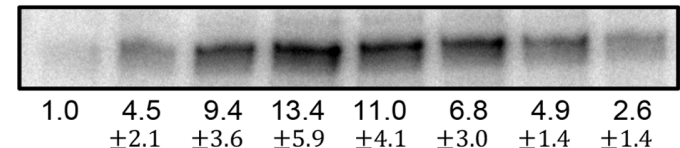

FIGURE 5 | Effects of diamide and monobromobimane, known as thiol-reactive electrophiles. S. coelicolor cells were treated with diamide (500 $\mu$ M; A) or monobromobimane (20 $\mathrm{MM}$; B) for 5-120 min, prior to RNA sample preparation. Results from three independent experiments were presented as described in Figure 3.

PMS is not sufficient for immediate disulfide bond formation in RsrA, considering that RsrA is relatively insensitive to hydrogen peroxide (Kang et al., 1999; Rajasekar et al., 2016).

\section{Redox Signaling of Benzoquinone and Plumbagin}

We then examined and compared the action modes of a benzoquinone and naphthoquinone plumbagin at subinhibitory doses (Supplementary Figure S2; Lee et al., 2015). As demonstrated in Figure 4A, BQ immediately activated the SoxR and SigR systems. In contrast, it induced the CatR system in a delayed fashion. This indicates that BQ is a potent RAC that immediately oxidizes $[2 \mathrm{Fe}-2 \mathrm{~S}]$ of SoxR, as well as a potent electrophile that can modify or form disulfide bonds in RsrA. Its ROS-producing activity seemed to either be relatively slow or occur through an indirect path via damaging intracellular redox homeostasis. The short duration of both SoxR and SigR activation by BQ suggests that it may be rapidly removed from the cell, possibly by the combined actions of an increased exporter (SoxR target) and mycothiol-mediated detoxification system (SigR target) (Antelmann et al., 2008; Park and Roe, 2008).

The effects of plumbagin are different from those of $B Q$. Plumbagin induces the SoxR and CatR systems immediately, whereas the SigR system is activated in a delayed fashion (Figure 4B). The activation profile of SoxR indicates that plumbagin is a potent RAC, which appears to be removed from the cell more slowly than BQ. Immediate induction of the CatR system suggests that plumbagin is an effective redox-cycling agent in S. coelicolor. The continued inactivation of CatR at later time points $(60-120 \mathrm{~min})$, when plumbagin is being removed, suggests that either the peroxide level is maintained to keep CatR inactive and/or that oxidized CatR is not rapidly replaced with the functional repressor CatR. In B. subtilis, the CatR ortholog PerR is known to be irreversibly oxidized and subject to degradation by LonA (Ahn and Baker, 2016). The delayed induction of the SigR target gene suggests that plumbagin may slowly shift redox homeostasis to favor disulfide formation in RsrA as an indirect consequence, rather than causing oxidation or modifying RsrA directly. Depletion of reduced MSH through S-alkylation could cause a shift in thiol redox homeostasis to favor disulfide formation in RsrA. Shutting off SigR induction at late time points suggests that thiol redox homeostasis is regained within $2 \mathrm{~h}$, most likely because of the restoration of MSH and reduction of protein thiols through the action of SigR target gene products (Park and Roe, 2008; Kim et al., 2012).

\section{Redox Signaling of Diamide and Monobromobimane in S. coelicolor}

The redox-signaling activities of diamide and monobromobimane $(\mathrm{mBBr})$, typically known as disulfideforming and S-alkylating electrophiles, respectively, were then examined at sub-inhibitory concentrations (Supplementary Figure S2). Figure 5A shows that diamide is a weak RAC at $0.5 \mathrm{mM}$, activating SoxR only marginally. It is, however, a potent activator of the SigR system, as previously observed. It did not induce the CatR system, indicating that it does not have any detectable redox-cycling activity. In contrast to diamide, $\mathrm{mBBr}$ did not activate SoxR (Figure 5B). It moderately activated the SigR system in an immediate and prolonged manner. This agrees with the suggestion that $\mathrm{mBBr}$ activates the SigR system by depleting the $\mathrm{MSH}$ pool for relatively long time (up to $80 \mathrm{~min}$ ) at $20 \mu \mathrm{M}$, which facilitates disulfide formation in RsrA (Park and Roe, 2008). Interestingly, $\mathrm{mBBr}$ induced the CatR system at late time points (Figure 5B). This suggests that prolonged depletion of $\mathrm{MSH}$ by $\mathrm{mBBr}$ resulted in the accumulation of peroxides. In contrast, diamide exerted direct effects on RsrA through immediate disulfide bond formation. The induced SigR system turned off completely within an hour because of disulfide 
A

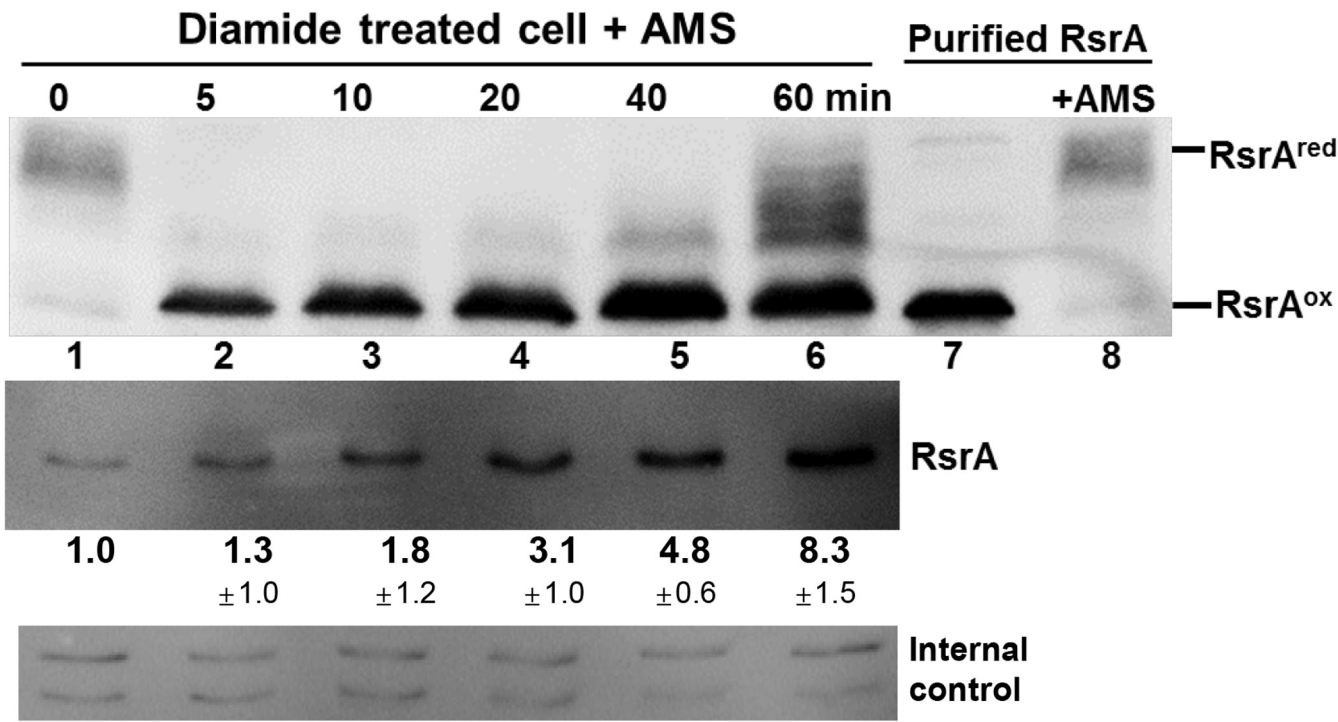

B

\section{Benzoquinone treated cell + AMS}

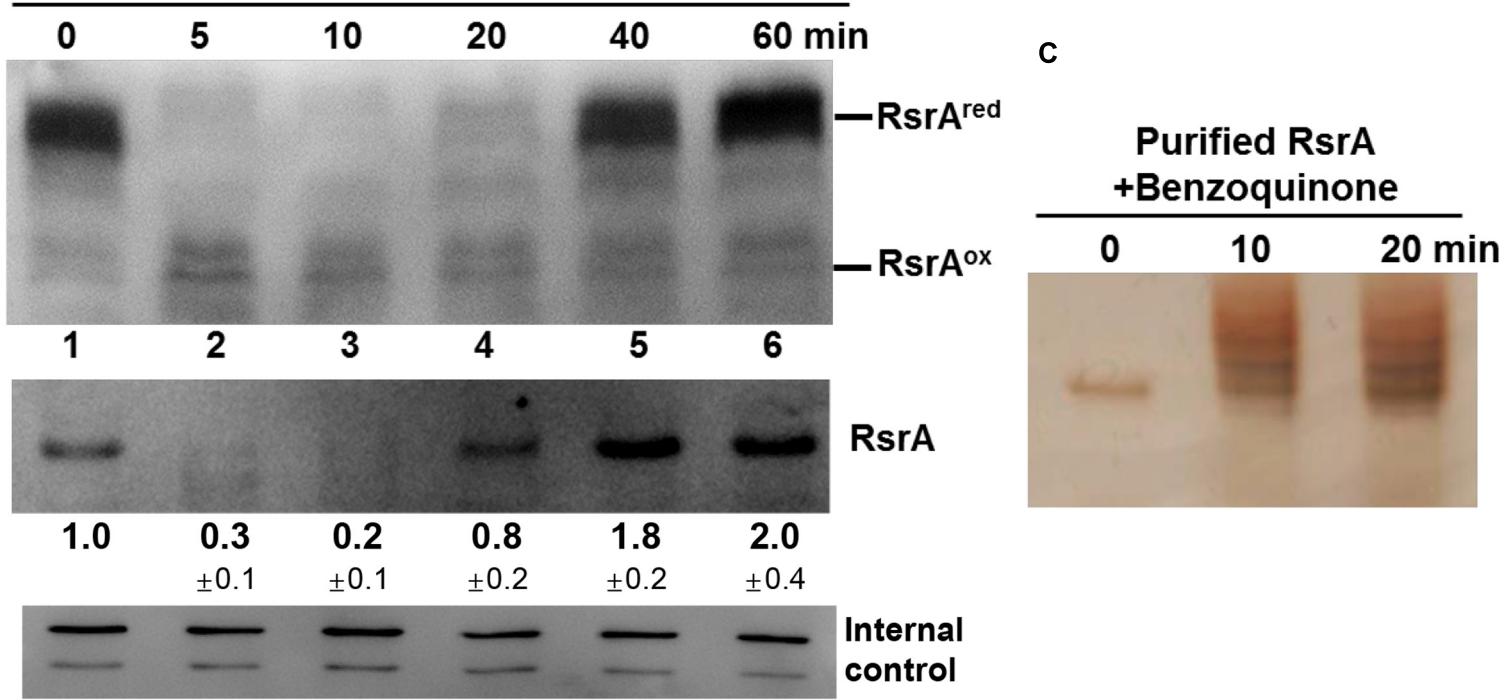

FIGURE 6 | Effects of thiol-reactive compounds on RsrA. Effects of diamide and benzoquinone on the redox and modification status of RsrA were examined in vivo and in vitro. (A) Cells were treated with diamide $(0.5 \mathrm{mM})$ for 5-60 min, followed by TCA precipitation and AMS modification of free thiols. Protein samples were resolved by SDS-PAGE, followed by Western blot analysis with anti-RsrA antibody (lanes 1-6). Purified reduced RsrA was either untreated or treated with AMS and run on the same gel as redox standards (lanes 7, 8). To determine the level of total RsrA protein in each sample, extracts from cells prior to TCA precipitation were analyzed in parallel by Western blot analysis (lower panel). The amount of RsrA protein relative to that in the untreated sample was determined from three independent experiments. The non-specific bands were shown at the bottom as internal controls. (B) Cells were treated with $50 \mu \mathrm{M}$ benzoquinone for 5-60 min and analyzed in the same way as in (A). The amount of RsrA was determined from four independent experiments. (C) Purified RsrA was treated with $50 \mu \mathrm{M}$ benzoquinone for 10 or $20 \mathrm{~min}$ and analyzed by SDS-PAGE followed by silver staining.

TABLE 1 | Detection of benzoquinone-conjugated cysteines in RsrA by LC-MS/MS.

\begin{tabular}{lccccccc}
\hline Cysteine position in RsrA & C3 & C11 & C31 & C41 & C44 & C61 \\
\hline Frequency of detection $^{\mathrm{a}}$ & $\mathrm{ND}^{\mathrm{b}}$ & $\mathrm{ND}$ & 3 & 2 & 4 & 14 \\
\hline
\end{tabular}

aThe number of times that the mass of the specific cysteine was detected to increase by 108.021 Da, with the SpecE value less than $1 E-10$. The raw dada for various peptides that contain modified cysteine residues was presented in the Supplementary Table S1 and Supplementary Figure S5.

bND*, non-detected. 
reduction of RsrA by thioredoxin systems and MSH (Kang et al., 1999; Park and Roe, 2008), accompanied by the removal of diamide. Among the induced SigR-target gene products, several nitroreductase candidates may function in degrading diamide, as observed for nitroreductases (AzoR1 and AzoR2) in B. subtilis (Antelmann et al., 2008).

\section{Monitoring ROS Generation by Fluorescence in S. coelicolor}

The ROS-generating ability of the RACs used in this study was examined using the fluorescent probe $2^{\prime}-7^{\prime}$-dichlorofluorescein diacetate $\left(\mathrm{DCFH}_{2}-\mathrm{DA}\right)$ as previously described (Lee et al., 2015). $\mathrm{DCFH}_{2}$ that penetrates the cell membrane is oxidized to fluorescent DCF by ROS and radicals (Winterbourn, 2014). Supplementary Figure S3 shows that only plumbagin and PMS generated detectable fluorescence $30 \mathrm{~min}$ post-treatment. These two chemicals induced the CatR system effectively (Figures 3 and $4 \mathrm{~B}$ ), consistent with the intracellular oxidation of $\mathrm{DCFH}_{2}$. However, the ability of BQ to induce the CatR system (Figure 4A) was not revealed by the fluorescence detection assay. Considering that BQ is a good superoxide producer with a one-electron redox potential of $+99 \mathrm{mV}$ (O'Brien, 1991) and is likely to produce peroxides, as supported by CatR induction, it appears that the fluorescence assay is not a sufficiently sensitive assay to monitor the ROS-generating ability of RACs in cells.

\section{Effects of Thiol-Reactive Compounds on RsrA}

Until now, inactivation of RsrA (or activation of SigR) has been shown to occur via disulfide bond formation, either directly by diamide or indirectly through MSH depletion by the S-alkylating electrophiles $N$-ethyl maleimide (NEM) and $\mathrm{mBBr}$ (Park and Roe, 2008; Rajasekar et al., 2016). Slow induction of the SigR system by plumbagin may be caused by a thiol redox shift due to $\mathrm{MSH}$ depletion (Figure 4B). The rapid and highly potent induction of the SigR system by BQ suggests its direct action on RsrA (Figure 4A). We therefore investigated the redox and modification status of RsrA in vivo following benzoquinone treatment, in comparison with that following diamide treatment. Immediately after treatment, the TCA-precipitated proteins were treated with AMS to alkylate reduced thiols, followed by Western blot analysis with polyclonal antibody against RsrA. One AMS adduct per thiol adds about $0.5 \mathrm{kDa}$ to the molecular weight of each protein and shifts protein mobility accordingly. For reduced RsrA with seven cysteine residues, up to seven AMS adducts can be formed theoretically. To provide mobility standards for the oxidized vs. reduced RsrA, purified RsrA, either non-treated or treated with AMS, were examined in parallel by SDS-PAGE (Supplementary Figure S4). The multiplicity of AMS-conjugated proteins caused less clear detection due to band broadening in Western blots than the unmodified proteins. The diamideoxidized RsrA did not interact with AMS, suggesting that the oxidized RsrA with only one or two disulfide bonds hindered AMS to modify the remaining free cysteine thiols. This coincides with a recent finding that the oxidized RsrA maintains the more packed structure than the reduced one (Rajasekar et al., 2016).

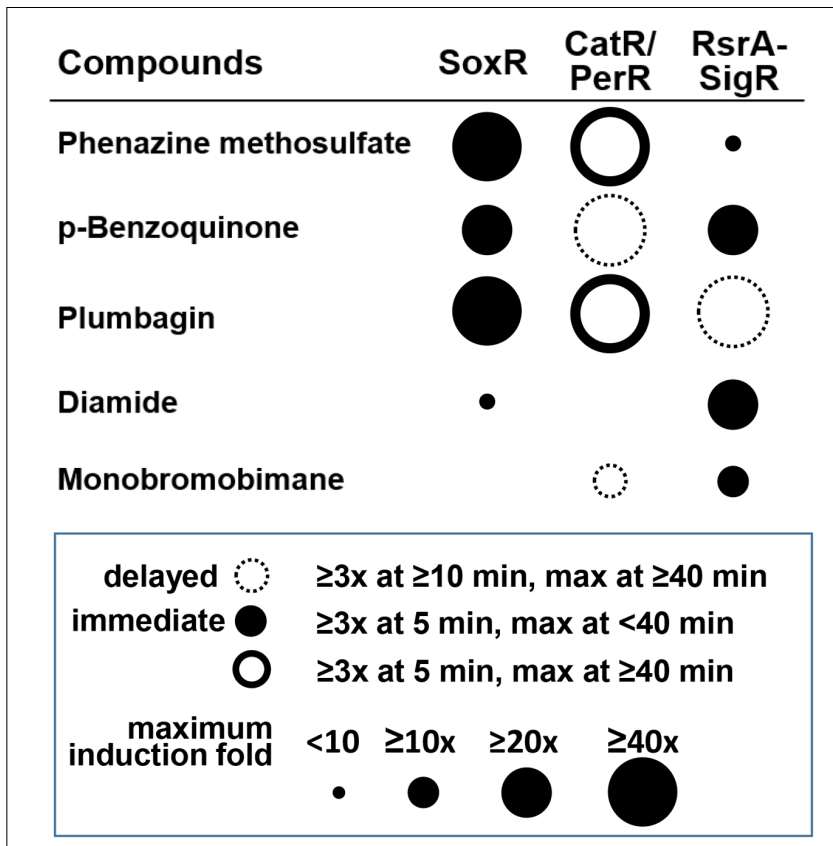

FIGURE 7 | Summary of the differential signaling effects of reactive compounds on SoxR, CatR/PerR, and RsrA. For each compound, the effectiveness in modulating the activity of each regulator was presented in terms of fold induction of the target gene (circle size) and the immediacy of the response (filled and empty circles for immediate and delayed responses, respectively). Induction ( $\geq 3$-fold) at $5 \mathrm{~min}$, with a maximum reached by $40 \mathrm{~min}$, was regarded as an immediate response. Induction at $\geq 10 \mathrm{~min}$, with a maximum reached by $\geq 40$ min was regarded as a delayed response. PMS and plumbagin caused prolonged CatR response (maximum at $\geq 40 \mathrm{~min}$ ), with rapid induction at $5 \mathrm{~min}$, which was represented by a solid-lined open circle.

Results shown in Figure 6A indicate that nearly all RsrA in the cell is in the reduced form (Figure 6A, lane 1). Upon diamide treatment, RsrA became oxidized within 5 min (lane 2). Reduced forms of RsrA appeared after $40 \mathrm{~min}$ and further increased at $60 \mathrm{~min}$. The amount of total RsrA protein in cell extracts before the addition of TCA and AMS was estimated in a separate Western blot analysis (Figure 6A, lower panel). As expected, the amount of RsrA steadily increased up to eightfold at $60 \mathrm{~min}$, consistent with the increase in $\operatorname{sig} R$-rs $r A$ transcripts by activated SigR (Paget et al., 1998; Kim et al., 2012).

Treatment with BQ produced an unexpected result. Immediately after treatment, the reduced RsrA band disappeared, accompanied with the appearance of a faint oxidized band (Figure 6B). The reduced band re-appeared at 40 min posttreatment. When the amount of RsrA in cell extracts for each sample was assessed by Western blot (Figure 6B, lower panel), we found that the level of RsrA decreased to $\sim 30 \%$ that of the untreated level at $5 \mathrm{~min}$ (lane 2). The protein level then increased steadily after $10 \mathrm{~min}$ to about twofold level at $60 \mathrm{~min}$ (lanes 3-6). The disappearance of RsrA-specific band can be postulated to be due to degradation and/or inefficient immune-detection of BQ-modified RsrA. Whether benzoquinone can form adducts on RsrA was examined by incubating $50 \mu \mathrm{M}$ BQ with purified RsrA in vitro, followed by SDS-PAGE. Silver staining of the gel 
showed that BQ caused formation of higher molecular weight forms of RsrA (Figure 6C). We analyzed BQ-treated RsrA by LC-MS/MS, which revealed that BQ formed adducts in at least 5 cysteine positions in RsrA (Table 1; Supplementary Figure S5; Supplementary Table S1). Therefore, it is very likely that BQ alkylates RsrA in vivo. Regardless of whether RsrA is oxidized or modified, the liberated SigR induces its target genes. As suggested by the results shown in Figure 4A, nearly all $\mathrm{BQ}$ is likely to be removed from cells by approximately $40 \mathrm{~min}$. The time course of the increase in the amount of RsrA and restoration of the reduced form of RsrA by about 40 min coincides with the induction profile of the sigRp2 promoter in vivo (Figure 4A). Therefore, the observed BQ effect reveals a new induction mechanism of SigR regulon by direct modification of RsrA. The antibody detected BQ-conjugated RsrA with significantly lesser efficiency than the unmodified form. Therefore, the fate of BQ-conjugated RsrA requires further systematic investigation.

Figure 7 summarizes the differential effects of each compound on the three regulators. The results indicate that the differential activities of RACs in cells are well-resolved by examining multiple regulators. The timing and magnitude of their actions and the kinds of regulators that they affect provide information on the possible chemical activity of each of these compounds in cells. Because the induced target genes usually encode proteins with defense functions against the damaging effect of reactive compounds at high doses, this analysis provides insight into the mechanisms of chemical toxicity of the compounds in cells. Responsive regulators in $S$. coelicolor cells unfolded some new activities and signaling pathways of these compounds. Further

\section{REFERENCES}

Ahn, B. E., and Baker, T. A. (2016). Oxidization without substrate unfolding triggers proteolysis of the peroxide-sensor. PerR. Proc. Natl. Acad. Sci. U.S.A. 113, E23-E31. doi: 10.1073/pnas.1522687112

Antelmann, H., Hecker, M., and Zuber, P. (2008). Proteomic signatures uncover thiol-specific electrophile resistance mechanisms in Bacillus subtilis. Expert Rev. Proteomics 5, 77-90. doi: 10.1586/14789450.5.1.77

Bae, J. B., Park, J. H., Hahn, M. Y., Kim, M. S., and Roe, J. H. (2004). Redoxdependent changes in RsrA, an anti-sigma factor in Streptomyces coelicolor: zinc release and disulfide bond formation. J. Mol. Biol. 335, 425-435. doi: 10.1016/j.jmb.2003.10.065

Bass, D. A., Parce, J. W., Dechatelet, L. R., Szejda, P., Seeds, M. C., and Thomas, M. (1983). Flow cytometric studies of oxidative product formation by neutrophils: a graded response to membrane stimulation. J. Immunol. 130, 1910-1917.

Bentley, S. D., Chater, K. F., Cerdeno-Tarraga, A. M., Challis, G. L., Thomson, N. R., James, K. D., et al. (2002). Complete genome sequence of the model actinomycete Streptomyces coelicolor A3(2). Nature 417, 141-147. doi: 10.1038/ 417141a

Brekasis, D., and Paget, M. S. (2003). A novel sensor of NADH/NAD+ redox poise in Streptomyces coelicolor A3(2). EMBO J. 22, 4856-4865. doi: 10.1093/emboj/ cdg453

Bus, J. S., and Gibson, J. E. (1984). Paraquat: model for oxidantinitiated toxicity. Environ. Health Perspect. 55, 37-46. doi: 10.1289/ehp. 845537

Castro, F. A., Mariani, D., Panek, A. D., Eleutherio, E. C., and Pereira, M. D. (2008). Cytotoxicity mechanism of two naphthoquinones (menadione and plumbagin) in Saccharomyces cerevisiae. PLoS ONE 3:e3999. doi: 10.1371/journal.pone. 0003999 systematic studies are in need to reveal the life spans of these compounds and the precise mechanisms associated with their secondary effects.

\section{AUTHOR CONTRIBUTIONS}

J-HR, K-LL, and J-SY conceived the project. J-SY, G-SO, K-LL, and AS performed the experiments. K-LL and J-HR wrote the manuscript.

\section{ACKNOWLEDGMENTS}

This work was supported by a grant (2014R1A2A1A01002846) from the Ministry of Science, ICT, and Future Planning and a grant (2011-0031960) for the Intelligent Synthetic Biology Center of Global Frontier Project to J-HR. G-SO was supported by a BK21-Plus Fellowship for graduate students in Biological Sciences at SNU. LC-MS/MS analysis was supported by proteomics core facility in the School of Biological Sciences at SNU, which is supported by the Center for RNA research, Institute of Basic Science.

\section{SUPPLEMENTARY MATERIAL}

The Supplementary Material for this article can be found online at: http://journal.frontiersin.org/article/10.3389/fmicb. 2017.00139/full\#supplementary-material

Crack, J. C., Munnoch, J., Dodd, E. L., Knowles, F., Al Bassam, M. M., Kamali, S., et al. (2015). NsrR from Streptomyces coelicolor is a nitric oxide-sensing [4Fe4S] cluster protein with a specialized regulatory function. J. Biol. Chem. 290, 12689-12704. doi: 10.1074/jbc.M115.643072

Dela Cruz, R., Gao, Y., Penumetcha, S., Sheplock, R., Weng, K., and Chander, M. (2010). Expression of the Streptomyces coelicolor SoxR regulon is intimately linked with actinorhodin production. J. Bacteriol. 192, 6428-6438. doi: 10.1128/ JB.00916-10

den Hengst, C. D., and Buttner, M. J. (2008). Redox control in actinobacteria. Biochim. Biophys. Acta 1780, 1201-1216. doi: 10.1016/j.bbagen.2008.01.008

Dietrich, L. E., Teal, T. K., Price-Whelan, A., and Newman, D. K. (2008). Redoxactive antibiotics control gene expression and community behavior in divergent bacteria. Science 321, 1203-1206. doi: 10.1126/science.1160619

Farr, S. B., and Kogoma, T. (1991). Oxidative stress responses in Escherichia coli and Salmonella typhimurium. Microbiol. Rev. 55, 561-585.

Fujikawa, M., Kobayashi, K., Tsutsui, Y., Tanaka, T., and Kozawa, T. (2016). Rational tuning of superoxide sensitivity in SoxR, the [2Fe-2S] transcription factor; implication of species-specific lysine residues. Biochemistry 56, 403-410. doi: 10.1021/acs.biochem.6b01096

Gaballa, A., Newton, G. L., Antelmann, H., Parsonage, D., Upton, H., Rawat, M., et al. (2010). Biosynthesis and functions of bacillithiol, a major low-molecularweight thiol in Bacilli. Proc. Natl. Acad. Sci. U.S.A. 107, 6482-6486. doi: 10.1073/ pnas. 1000928107

Gu, M., and Imlay, J. A. (2011). The SoxRS response of Escherichia coli is directly activated by redox-cycling drugs rather than by superoxide. Mol. Microbiol. 79, 1136-1150. doi: 10.1111/j.1365-2958.2010.07520.x

Hahn, J. S., Oh, S. Y., Chater, K. F., Cho, Y. H., and Roe, J. H. (2000). $\mathrm{H} 2 \mathrm{O} 2$-sensitive fur-like repressor CatR regulating the major catalase gene in Streptomyces coelicolor. J. Biol. Chem. 275, 38254-38260. doi: 10.1074/jbc. M006079200 
Hahn, J. S., Oh, S. Y., and Roe, J. H. (2002). Role of OxyR as a peroxide-sensing positive regulator in Streptomyces coelicolor A3(2). J. Bacteriol. 184, 5214-5222. doi: 10.1128/JB.184.19.5214-5222.2002

Hassan, H. M., and Fridovich, I. (1979). Paraquat and Escherichia coli. Mechanism of production of extracellular superoxide radical. J. Biol. Chem. 254, 10846-10852.

Hillion, M., and Antelmann, H. (2015). Thiol-based redox switches in prokaryotes. Biol. Chem. 396, 415-444. doi: 10.1515/hsz-2015-0102

Hopwood, D. A. (2007). Streptomyces in Nature and Medicine. Oxford: Oxford University Press.

Imlay, J. A. (2013). The molecular mechanisms and physiological consequences of oxidative stress: lessons from a model bacterium. Nat. Rev. Microbiol. 11, 443-454. doi: 10.1038/nrmicro3032

Jacobs, A. T., and Marnett, L. J. (2010). Systems analysis of protein modification and cellular responses induced by electrophile stress. Acc. Chem. Res. 43, 673-683. doi: 10.1021/ar900286y

Kang, J. G., Paget, M. S., Seok, Y. J., Hahn, M. Y., Bae, J. B., Hahn, J. S., et al. (1999). RsrA, an anti-sigma factor regulated by redox change. EMBO J. 18, 4292-4298. doi: 10.1093/emboj/18.15.4292

Keston, A. S., and Brandt, R. (1965). The fluorometric analysis of ultramicro quantities of hydrogen peroxide. Anal. Biochem. 11, 1-5. doi: 10.1016/00032697(65)90034-5

Kieser, T., Bibb, M. J., Buttner, M. J., Chater, K. F., and Hopwood, D. A. (2000). Practical Streptomyces Genetics. Norwich: John Innes Foundation.

Kim, M. S., Dufour, Y. S., Yoo, J. S., Cho, Y. B., Park, J. H., Nam, G. B., et al. (2012). Conservation of thiol-oxidative stress responses regulated by SigR orthologues in actinomycetes. Mol. Microbiol. 85, 326-344. doi: 10.1111/j.1365-2958.2012. 08115.x

Kosower, N. S., and Kosower, E. M. (1995). Diamide: an oxidant probe for thiols. Methods Enzymol. 251, 123-133. doi: 10.1016/0076-6879(95) 51116-4

Kosower, N. S., Kosower, E. M., Newton, G. L., and Ranney, H. M. (1979). Bimane fluorescent labels: labeling of normal human red cells under physiological conditions. Proc. Natl. Acad. Sci. U.S.A. 76, 3382-3386. doi: 10.1073/pnas.76. 7.3382

Lee, J. W., and Helmann, J. D. (2006). The PerR transcription factor senses H2O2 by metal-catalysed histidine oxidation. Nature 440, 363-367. doi: 10.1038/ nature 04537

Lee, K. L., Singh, A. K., Heo, L., Seok, C., and Roe, J. H. (2015). Factors affecting redox potential and differential sensitivity of SoxR to redox-active compounds. Mol. Microbiol. 97, 808-821. doi: 10.1111/mmi.13068

Li, W., Bottrill, A. R., Bibb, M. J., Buttner, M. J., Paget, M. S., and Kleanthous, C. (2003). The Role of zinc in the disulphide stress-regulated anti-sigma factor RsrA from Streptomyces coelicolor. J. Mol. Biol. 333, 461-472. doi: 10.1016/j. jmb.2003.08.038

Naseer, N., Shapiro, J. A., and Chander, M. (2014). RNA-Seq analysis reveals a six-gene SoxR regulon in Streptomyces coelicolor. PLoS ONE 9:e106181. doi: 10.1371/journal.pone.0106181

Newton, G. L., Buchmeier, N., and Fahey, R. C. (2008). Biosynthesis and functions of mycothiol, the unique protective thiol of Actinobacteria. Microbiol. Mol. Biol. Rev. 72, 471-494. doi: 10.1128/MMBR.00008-08

Nishikimi, M., Appaji, N., and Yagi, K. (1972). The occurrence of superoxide anion in the reaction of reduced phenazine methosulfate and molecular oxygen. Biochem. Biophys. Res. Commun. 46, 849-854. doi: 10.1016/S0006-291X(72) 80218-3

O’Brien, P. J. (1991). Molecular mechanisms of quinone cytotoxicity. Chem. Biol. Interact. 80, 1-41. doi: 10.1016/0009-2797(91)90029-7
Oh, S. Y., Shin, J. H., and Roe, J. H. (2007). Dual role of OhrR as a repressor and an activator in response to organic hydroperoxides in Streptomyces coelicolor. J. Bacteriol. 189, 6284-6292. doi: 10.1128/JB.00632-07

Okegbe, C., Sakhtah, H., Sekedat, M. D., Price-Whelan, A., and Dietrich, L. E. (2012). Redox eustress: roles for redox-active metabolites in bacterial signaling and behavior. Antioxid. Redox Signal. 16, 658-667. doi: 10.1089/ars.2011.4249

Paget, M. S., Kang, J. G., Roe, J. H., and Buttner, M. J. (1998). sigmaR, an RNA polymerase sigma factor that modulates expression of the thioredoxin system in response to oxidative stress in Streptomyces coelicolor A3(2). EMBO J. 17, 5776-5782. doi: 10.1093/emboj/17.19.5776

Parent, A., Caux-Thang, C., Signor, L., Clemancey, M., Sethu, R., Blondin, G., et al. (2013). Single glutamate to aspartate mutation makes ferric uptake regulator (Fur) as sensitive to $\mathrm{H} 2 \mathrm{O} 2$ as peroxide resistance regulator (PerR). Angew. Chem. Int. Ed. 52, 10339-10343. doi: 10.1002/anie.201304021

Park, J. H., and Roe, J. H. (2008). Mycothiol regulates and is regulated by a thiolspecific antisigma factor RsrA and sigma(R) in Streptomyces coelicolor. Mol. Microbiol 68, 861-870. doi: 10.1111/j.1365-2958.2008.06191.x

Pierson, L. S. I. I. I., and Pierson, E. A. (2010). Metabolism and function of phenazines in bacteria: impacts on the behavior of bacteria in the environment and biotechnological processes. Appl. Microbiol. Biotechnol. 86, 1659-1670. doi: 10.1007/s00253-010-2509-3

Rajasekar, K. V., Zdanowski, K., Yan, J., Hopper, J. T., Francis, M. L., Seepersad, C., et al. (2016). The anti-sigma factor RsrA responds to oxidative stress by reburying its hydrophobic core. Nat. Commun. 7:12194. doi: 10.1038/ ncomms 12194

Rudolph, T. K., and Freeman, B. A. (2009). Transduction of redox signaling by electrophile-protein reactions. Sci. Signal. 2:re7. doi: 10.1126/scisignal.290re7

Sheplock, R., Recinos, D. A., Mackow, N., Dietrich, L. E., and Chander, M. (2013). Species-specific residues calibrate SoxR sensitivity to redox-active molecules. Mol. Microbiol. 87, 368-381. doi: 10.1111/mmi.12101

Shin, J. H., Singh, A. K., Cheon, D. J., and Roe, J. H. (2011). Activation of the SoxR regulon in Streptomyces coelicolor by the extracellular form of the pigmented antibiotic actinorhodin. J. Bacteriol. 193, 75-81. doi: 10.1128/JB.00965-10

Singh, A. K., Shin, J. H., Lee, K. L., Imlay, J. A., and Roe, J. H. (2013). Comparative study of SoxR activation by redox-active compounds. Mol. Microbiol. 90, 983-996. doi: 10.1111/mmi.12410

Tucker, N. P., Hicks, M. G., Clarke, T. A., Crack, J. C., Chandra, G., Le Brun, N. E., et al. (2008). The transcriptional repressor protein NsrR senses nitric oxide directly via a [2Fe-2S] cluster. PLOS ONE 3:e3623. doi: 10.1371/journal.pone. 0003623

Watanabe, S., Kita, A., Kobayashi, K., and Miki, K. (2008). Crystal structure of the [2Fe-2S] oxidative-stress sensor SoxR bound to DNA. Proc. Natl. Acad. Sci. U.S.A. 105, 4121-4126. doi: 10.1073/pnas.0709188105

Winterbourn, C. C. (2014). The challenges of using fluorescent probes to detect and quantify specific reactive oxygen species in living cells. Biochim. Biophys. Acta 1840, 730-738. doi: 10.1016/j.bbagen.2013.05.004

Conflict of Interest Statement: The authors declare that the research was conducted in the absence of any commercial or financial relationships that could be construed as a potential conflict of interest.

Copyright (c) 2017 Lee, Yoo, Oh, Singh and Roe. This is an open-access article distributed under the terms of the Creative Commons Attribution License (CC BY). The use, distribution or reproduction in other forums is permitted, provided the original author(s) or licensor are credited and that the original publication in this journal is cited, in accordance with accepted academic practice. No use, distribution or reproduction is permitted which does not comply with these terms. 